\title{
Mid-wall fibrosis on delayed enhancement CMR - a marker for adverse left ventricular chamber remodeling independent of cardiomyopathic etiology
}

\author{
Jiwon Kim², Jonathan D Kochav' ${ }^{2}$, Sergey Gurevich¹, Evelyn M Horn', Parag Goyal', Maya M Petashnick' , \\ Anika Afroz ${ }^{1}$, Peter M Okin', Richard B Devereux', Jonathan W Weinsaft ${ }^{1,2}$
}

From 17th Annual SCMR Scientific Sessions

New Orleans, LA, USA. 16-19 January 2014

\section{Background}

Mid-wall fibrosis (MWF) is a hallmark of non-ischemic cardiomyopathy (NICM) that confers increased risk for sudden cardiac death and mortality. The relationship between MWF and left ventricular (LV) remodeling is unknown.

\section{Methods \\ The population comprised patients with advanced systo- lic dysfunction (LVEF $\leq 40 \%)$ undergoing CMR (1.5T, General Electric Signa). Ischemic vs. NICM etiology was classified in accordance with established convention based on obstructive CAD on invasive angiography. Delayed enhancement CMR (IR-GRE acquired 10-30 minutes post gadolinium $[0.2 \mathrm{mmol} / \mathrm{kg}]$ ) was used to identify MWF, defined as hyperenhancement confined to the mid-myocardial or epicardial aspect of the inter- ventricular septum. LV mass and chamber volume were quantified by planimetry of contiguous SSFP cine-CMR short axis slices, with ejection fraction (EF) calculated as the proportional difference between end-diastolic (EDV) and end-systolic (ESV) volumes.}

\section{Results}

523 patients $(61 \pm 14$ yo, $72 \%$ M, $66 \%$ ischemic CM) were studied: MWF was present in $16 \%$, and was 6 -fold more common in patients with angiographically classified NICM (37\% vs. 6\%; $\mathrm{p}<0.001)$. Regarding LV remodeling,

${ }^{2}$ Medicine, Memorial Sloan Kettering Cancer Center, New York, New York,

USA

Full list of author information is available at the end of the article
MWF was associated with higher EDV $(134 \pm 39 \mathrm{ml}$ vs. $114 \pm 34 \mathrm{ml} ; \mathrm{p}<0.001)$ and LV mass $(102 \pm 24$ vs. $96 \pm$ 28 gm; $\mathrm{p}<0.001)$ and lower LVEF $(26 \pm 8 \%$ vs. $30 \pm 8 \%$; $\mathrm{p} \leq 0.05$ ). MWF was nearly 3 -fold more common among patients in the highest tertile of EDV vs. the remainder of the population $(29 \%$ vs. $10 \%$; p < 0.001$)$. Multivariate regression analysis was performed to further assess markers for MWF: Restricted to imaging indices, results (Table 1A) demonstrated EF and EDV to be independently associated with MWF (OR $=1.46$, CI 1.03-2.10; $\mathrm{p}$ $<0.05$, OR $=1.13$, CI 1.04-1.20; $\mathrm{p}<0.05$, respectively) after controlling for mass $(\mathrm{OR}=0.95$, CI $0.85-1.00$; $\mathrm{p}=0.29$ ). Regarding clinical variables, results (Table $1 \mathrm{~B}$ ) confirmed a strong association with $\mathrm{NICM}(\mathrm{OR}=8.4, \mathrm{CI}$ 4.78-14.72; $\mathrm{p}<0.001)$, independent of other clinical indices. A combined model incorporating both clinical and imaging variables demonstrated both NICM and LV volume to be independently associated with MWF even after controlling for EF (Table 1C). Overall strength of the combined clinical/imaging $\left(\chi^{2}=91.2 ; \mathrm{p}<0.001\right)$ model for MWF was higher than that of isolated clinical $\left(\chi^{2}=76.7 ; \mathrm{p}<0.001\right)$ and imaging $\left(\chi^{2}=26.0 ; \mathrm{p}<0.001\right)$ models.

\section{Conclusions}

Among patients with advanced cardiomyopathy, MWF is associated with advanced LV chamber dilation independent of severity of LV dysfunction and cardiomyopathic etiology. 
Table 1 Multivariate Regression for Prediction of LV MWF

\begin{tabular}{|c|c|c|c|}
\hline 1A. Imaging & (Model $\chi^{2}=26.0, p<0.001$ ) & & \\
\hline Variable & Odds Ratio & 95\% Confidence Interval & $\mathbf{P}$ \\
\hline LV Ejection Fraction (per 10\% decrement) & 1.46 & $1.03-2.10$ & $<0.05$ \\
\hline LV End-Diastolic Volume (per 10 ml/m2) & 1.13 & $1.04-1.20$ & $<0.05$ \\
\hline Myocardial Mass (per 10 gm/m2) & 0.95 & $0.85-1.00$ & 0.29 \\
\hline 1B. Clinical & (Model $\chi^{2}=76.7, p<0.001$ ) & & \\
\hline Variable & Odds Ratio & 95\% Confidence Interval & $P$ \\
\hline Hypertension & 0.10 & $0.36-1.10$ & 0.10 \\
\hline Hypercholesterolemia & 0.94 & $0.59-1.78$ & 0.94 \\
\hline Age (years) & 0.70 & $0.99-1.00$ & 0.70 \\
\hline Non-Ischemic Etiology & 8.4 & $4.78-14.72$ & $<0.001$ \\
\hline 1C. Integrated Clinical/Imaging & (Model $\left.\chi^{2}=91.2, p<0.001\right)$ & & \\
\hline Variable & Odds Ratio & 95\% Confidence Interval & $P$ \\
\hline LV Ejection Fraction (per 10\% decrement) & 1.22 & $0.84-1.78$ & 0.29 \\
\hline LV End-Diastolic Volume (10 ml/m2) & 1.11 & $1.03-1.20$ & $<0.05$ \\
\hline Non-Ischemic Etiology & 8.22 & $4.75-14.2$ & $<0.001$ \\
\hline
\end{tabular}

\section{Funding}

National Institutes of Health (K23 HL102249-01).

\section{Authors' details}

${ }^{1}$ Medicine, Weill Cornell Medical College, New York, New York, USA.

${ }^{2}$ Medicine, Memorial Sloan Kettering Cancer Center, New York, New York, USA.

Published: 16 January 2014

\section{doi:10.1186/1532-429X-16-S1-023}

Cite this article as: Kim et al:: Mid-wall fibrosis on delayed enhancement

CMR - a marker for adverse left ventricular chamber remodeling

independent of cardiomyopathic etiology. Journal of Cardiovascular

Magnetic Resonance 2014 16(Suppl 1):O23.

Submit your next manuscript to BioMed Central and take full advantage of:

- Convenient online submission

- Thorough peer review

- No space constraints or color figure charges

- Immediate publication on acceptance

- Inclusion in PubMed, CAS, Scopus and Google Scholar

- Research which is freely available for redistribution

Submit your manuscript at www.biomedcentral.com/submit
C Biomed Central 